\title{
Uniqueness of solutions for a fractional thermostat model
}

\section{J. Caballero, J. Harjani and K. Sadarangani}

\section{ABSTRACT.}

In this paper, we present a sufficient condition for the uniqueness of solutions to a nonlocal fractional boundary value problem which can be considered as the fractional version to the thermostat model. As application of our result, we study the eigenvalues problem associated and, moreover, we get a Lyapunov-type inequality.

Acknowledgements. The second and third author were partially supported by project MTM 2016-79436-P.

\section{REFERENCES}

[1] Ahmad, B., Sharp estimates for the unique solution of two-point fractional-order boundary value problems, Appl. Math. Lett., 65 (2017), 77-82

[2] Cabrera, I. J., Rocha, J. and Sadarangani, K. B., Lyapunov type inequalities for a fractional thermostat model, RACSAM, 112 (2018), 17-24

[3] Ferreira, R. A. C., Note on a uniqueness result for a two-point fractional boundary value problem, Appl. Math. Lett., 79 (2019), 75-78

[4] Ferreira, R. A. C., Existence and uniqueness of solutions for two-point fractional boundary value problems, Electron. J. Differential Equations, 2016, No. 202, 5 pp.

[5] Guidotti, P. and Merino, S., Gradual loss of positivity and hidden invariant cones in a scalar heat equation, Diff. Integr. Equ., 13 (2000), 1551-1568

[6] Kelley, W. G. and Peterson, A. C., The theory of differential equations, Second edition, Universitext Springer, New York, 2010

[7] Kilbas, A. A., Srivastava, H. M. and Trujillo, J. J., Theory and applications of fractional differential equations, North-Holland Mathematics Studies, vol. 204, Elsevier Science B. V. Amsterdam (2006)

[8] Podlubny, I., Fractional differential equations, Mathematics in Sciences and Engineering, vol. 198, Academic, San Diego (1999)

\section{DEPARTMENT OF MATHEMATICS}

UNIVERSITY OF LAS PALMAS DE GRAN CANARIA

CAmpus de Tafira Baja, 35017 Las Palmas de Gran Canaria, Spain

Email address: josefa.caballero@ulpgc.es

Email address: jharjaniedma.ulpgc.es

Email address: ksadaranedma.ulpgc.es

Received: 13.02.2020; In revised form: 11.06.2020; Accepted: 11.06.2020

2010 Mathematics Subject Classification. 49L20, 47H10.

Key words and phrases. Fractional differential equation, thermostat model, eigenvalue, Lyapunov-type inequality.

Corresponding author: Jackie Harjani; jharjani@dma.ulpgc.es 